\title{
POLICE REFORM: PROBLEMS OF GOVERNANCE AND ACCOUNTABILITY MANAGEMENT CHALLENGES SURROUNDING CURRENT PROPOSALS FOR POLICE RESTRUCTURING*
}

This article considers the current decision of the Home Secretary to scrap the 43 police forces and replace them with 12-15 regional strategic police forces. This follows on from the recent report of HMIC, entitled Closing the Gap, published in September 2005, which was to conclude that as currently constituted the police structure for England and Wales was no longer 'fit for purpose'. Using the ability of police services to provide an effective response to NIM Level 2 crime as a yardstick, HMIC was to find that any force with fewer than 4,000 police officers would be unlikely to be able to provide an adequate response.

One consequence of the report and the Home Secretary's response to it has been the request made to all police authorities and forces to present a business case to the Home Office by the end of 2005 identifying the future structure of policing in the region and the pattern of amalgamation they might favour. In the course of this exercise it was to be found that alternatives to amalgamation, collaboration and federation, had both been closed down by the Home Secretary, who has concluded that only the option of amalgamation was now acceptable to his department.

Subsequently it was to be learned that a number of factors influencing HMIC's 2005 report obtained that had not been taken into account. These included the decision on the part of HMIC specifically not to include the written section on force collaboration within the final report. Nor, it was also to be discovered, had recognition been given within the report to the expectation that implementation was to be carried out in conjunction with comprehensive Workforce Modernisation. A leaked memorandum from ODPM in late 2005 that local government reform was now under active consideration was also to undermine the earlier assumption on the part of HMIC that no 
plans for local government reform were currently planned and that unilateral police reorganisation was therefore appropriate.

\section{Introduction}

In what has proved to be almost unprecedented in terms of speed of implementation, the Home Secretary has given deadlines for all forces to provide him with plans for future amalgamations on a regional basis. This follows on from HMIC's report Closing the Gap (2005) which was to find that, as currently constituted, many police forces were unable in terms of manpower and resources to support a range of protective services and this had to be addressed with some degree of urgency. In response to this, many police authorities, albeit reluctantly, have agreed to draw up business plans for restructuring. However, it has also become apparent in the short period within which this exercise has been conducted that there are significant differences between tripartite members as to what form the eventual outcome of reform is likely to take.

Within ACPO, for example, there appears to be a view that reform will merely involve a significant enlargement of current police forces, with a stronger 'protective service' element created within these forces. It is clear, however, that this perception is not shared by other tripartite members, not least among members of the Home Office Ministerial Team, one of whom has argued that reform will necessarily involve a quite fundamental reorganisation of police service delivery. The 'reconfiguration' of policing, Hazel Blears has stated, must ensure that the police service does not end up with bigger versions of what it already has. She has stressed that to reconfigure policing is not just a matter of 'merging together' (Pertile, 2005a).

The Minister's perception of the reconfiguration process is linked of course to the decision to direct much more attention to and investment in National Intelligence Model Level 2 crime while also rolling out the new Neighbourhood Policing strategy. Investing in protective services cannot, it would appear, therefore take place at the expense of local neighbourhood policing. This, the Minister has stated, remains at the hub of the reform process.

\section{Sleepless Nights}

Yet it is also evident that the potential tensions generated by a concurrent emphasis on both NIM Level 2 and Level 1 crime within police forces could create significant problems in the overall delivery of police services to the public. These are likely 
to lead to many more 'sleepless nights' for the Inspector of Constabulary, whose review of today's police forces triggered the current restructuring exercise, than those already experienced by that officer to date (Pertile, 2005b).

It is also evident that in the preparation of the HMIC report Closing the Gap there have been some notable omissions. While police authorities, for instance, were ostensibly to be given the opportunity to identify both collaboration and federation with other local police forces as an alternative to the creation of strategic forces, these options were to be quickly closed down by the Home Secretary. This may have reflected an earlier decision within HMIC not to include the written section on 'collaboration' within the final report.

Neither was it to be made clear that much of what was to be argued within the same report was predicated on the comprehensive implementation of the 'workforce modernisation' programme now being piloted in some police forces. Workforce modernisation, particularly that pertaining to a significant increase in the employment of PCSOs was presumably seen as essential, not least because of the significant manpower investment that building up protective services would necessarily involve. Currently that is only likely to be achieved by substantial abstractions from current visible policing strength. Inevitably this could seriously impact on Level 1 policing while severely eroding the effectiveness of the planned implementation of future neighbourhood policing strategies.

\section{The Absence of a Strategic Tier of Government}

The recent HMIC report (2005) mentioned above has been the primary driver for reform and the planned creation of 'strategic police forces.. This report has identified serious weaknesses in the ability of many police forces to respond to 'Level 2' crime and recommends restructuring of police forces to enable the police service to deal effectively with 'protective services' in England and Wales.

As is quickly apparent within HMIC's report, the emphasis is quite understandably almost entirely directed towards operational policing matters and does not seek to address issues of future police governance that will be generated by the proposed restructuring of police forces. No recommendations are made concerning future police governance of the 'strategic forces' or indeed of local policing arrangements.

Although a number of options were to be identified within HMIC's report concerning future police structures, which 
included the option of closer collaboration, the Home Office has already indicated that it has a preference for regional strategic police forces.

The 'Strategic Police Force' option, it is argued, will enable all restructured police forces to provide adequate 'protective services'. While providing such a service the proposed structures will inevitably be extremely remote from local communities and indeed current local government. This matter becomes more pressing when it is recognised that outside regional government offices there is no political or administrative infrastructure to support the proposed new policing arrangements. It is as yet unclear what precise relationship will be established between the planned 'Police Commissioners' made responsible for managing the new regional forces and either regional government office or any regional strategic authority.

The planned restructuring at regional level for policing occurs at a time when the public in the north-east have demonstrated a pronounced rejection by way of referendum of proposed regional government bodies as recommended by the Office of the Deputy Prime Minister (ODPM). In the absence of a regional authority the expectation must be that strategic police forces will be matched by the creation of 'regional police authorities' that can be expected to be as remote geographically and administratively as will the proposed police commissioners.

In defence of the effective removal of police governance from local authorities and communities, HMIC's report goes to some length to stress that the reform of police structures can be embarked upon because of the stability demonstrated at a local level by Basic Command Units (BCUs), which now operate across all police forces.

\section{Current Confusion of the Role and Status of the BCU}

The emphasis placed within the HMIC report on the BCU structure and its stability is used as a defence for the proposed strategic restructuring of police forces. Yet it is evident that outside unitary authorities and the metropolitan areas BCUs have not to date exhibited anything like the level of stability to which HMIC lays claim on their behalf. Indeed the recent history of BCUs in the provinces has been one of constant change and disruption as BCU boundaries have been significantly and regularly altered by police force senior management teams (Loveday, 2005).

Clear evidence of the problems surrounding BCU boundaries was to be provided within the Home Secretary's ACPO speech at 
Birmingham in 2005. Here the Home Secretary was to request specifically that BCU boundaries should be drawn in such a way by SMT as to encourage 'coterminosity of boundaries' between the BCU and the local authority. This was to be followed by a letter sent to the ACPO Chair inviting that officer to request that all forces should identify coterminosity with local authorities as an immediate aim, particularly those dozen or so forces that had to date failed entirely to establish this at BCU level.

The precise role and function of the BCU is also as yet to be fully determined. This is currently reflected in the absence of any consensus as to what constitutes a viable size for a BCU. To date, as determined by police establishments, numbers identified within the police service as necessary for supporting viable BCUs has moved from 250 police officers in the early 1990s to over 1,000 by the end of that decade (Loveday, 2005:4). However, as with police forces the current pressure placed on BCUs is towards their further enlargement.

Other than that developed by the Police Superintendents Association (2004), very little analysis has been conducted into what is a viable size for a BCU. However, the primary purpose of the BCU was by way of flattening hierarchies to enable local commanders to effectively oversee and manage the local unit of policing. Nevertheless the ability of this officer to effectively manage units of policing involving establishments of 1,000 and above is clearly questionable. Whereas in Bristol Central police area there is a police establishment of over 1,000 and several hundred support staff, the 'BCU' might be more accurately designated a 'city police force' as it no longer exhibits the features of a police command as originally devised for a BCU.

\section{Limitations of BCU Function within Non-Metropolitan Counties and the Problem of District Authority Boundaries}

There are currently additional problems that are closely linked to the current and future roles of the BCU. These relate almost wholly to non-metropolitan counties where a two-tier division of service delivery responsibilities pertains. Here the very size and number of local district authorities can make the creation of coterminous boundaries difficult if not impossible to achieve.

One consequence of the number and size of local district councils is that currently most BCUs can expect to host a number of local district councils within their police boundary. This can prove to be problematical for the local police management team, particularly in the context of Crime and Disorder Reduction Partnerships (CDRP) work when local district aims 
and expectations concerning crime reduction strategies can differ significantly. It is also now accepted that for CDRP work to succeed there is a clear need for the BCU boundary to be coterminous with that of one local authority (Police Superintendents Association, 2004).

It is of interest within this context that the Police Superintendents Association has recently concluded that in relation to the delivery of effective policing the need for coterminous boundaries is the single most critical factor in determining whether a BCU is likely to deliver that policing (Police Superintendents Association, 2004). Interestingly, to date HMIC has never identified this as a measure of effectiveness and has also failed to collect data from police forces on this important element of contemporary policing.

From the foregoing it would appear that any suggestion that BCU structures exhibit stability within the non-metropolitan context would be wholly misleading. As CDRP delivery is district driven there is a real need for a wider strategic oversight that is able both to rise above local district level and provide a structure for police governance at sub-regional level.

A number of commentators on police reform while arguing for structural reform have done so on the basis of further local government reorganisation (O'Byrne, 2001; Loveday 2004; 2005). Indeed it could be argued that reform of police structures can only be successfully implemented if pursued in conjunction with local government reorganisation, which would, in this case, be linked to ending the two-tier division of local government by the creation of unitary authorities. These could be expected to sustain a BCU structure successfully while also providing a future basis for local police governance.

\section{Some Consequences of Non-reform of Local Government Structures}

HMIC's 2005 report was to note that there was no plan currently under consideration within ODPM for local government reorganisation. This in part was to be used as a justification for unilateral police reform. Subsequently, however, a 'leak' of minutes from ODPM Minister David Milliband was to demonstrate that reform of local government to create one-tier unitary authorities was in fact under active consideration and followed on from an earlier review of the current structure announced early on in 2005 (Loveday, 2005). This might suggest that police reform could benefit from following on from local government reorganisation rather than preceding it. 
However, at this point such local authority reorganisation yet remains a matter of speculation. One consequence of non-reform must be that with the removal upward to regional level of strategic police forces there will inevitably be a new and significant 'gap' created at local level in terms of both police governance and the work of CDRPs. These responsibilities cannot be exercised by local district councils as currently constituted, not least because their current boundaries rarely match that of local BCUs.

For this reason among others there will be a clear need at county council level for a body which is able to provide a police governance role while also monitoring and overseeing district crime reduction strategies within the county boundary. This responsibility would expect to remain with the county council, at least until such time as local government reorganisation was either planned or implemented. Currently within the nonmetropolitan areas there is no other body that could conceivably 'close the gap' generated at the local level as a result of the Home Secretary's commitment to the creation of strategic forces.

There are additional factors which are likely to become immediately relevant as strategic forces are established. These relate to the consequences of the expected creation of resilient and proactive policing units at strategic level that are able to provide adequate protective services but that also encompass the 'Neighbourhood Policing Strategy' which will be rolled out between 2006 and 2008.

Although some cost savings of the restructuring plans have been identified within HMIC's report it is evident that little or no reference has been made to assessing the impact of earlier police reorganisation on police service delivery which was in financial terms to prove not insignificant. The big amalgamations achieved in the 1970s also came at some considerable cost. This was to be best evidenced in the rapid decline in police patrol activity (visible policing) that could be sustained by the new and bigger police forces that emerged from police force amalgamation at this time.

While technology and the use of mobile patrol was often identified as an explanation for this decline, the major factor explaining this was, in fact, the rise of specialist police squads and units which larger police forces could now more easily sustain (Young, 1991: 329). The proliferation of specialist units offered career opportunities and professional career advancement that patrol activity increasingly denied police officers. One 
consequence of this, it has been argued by a former senior police officer, was that in places foot patrol very quickly became, 'almost a memory' (Young, 1991: 330)

\section{Potential Impact of NIM Level 2 Specialisation on Visible Policing}

The experience of the last reorganisation may need to be examined in the light of the proposed functions of the "strategic forces' which are almost entirely directed at 'Level 2 NIM'. Planned police units each made responsible for a specific protective service are also expected to support a level of 'overcapacity' to enable them to respond to any demand placed on them. There will not be, in the phrase used by HMIC, any 'double-hatting' among police personnel.

The planned role of the 'new' specialist units may serve, however, to generate real tensions at a local level particularly in relation to Neighbourhood Policing. This is because police career opportunities inevitably will be seen as more achievable through the new specialised units at 'strategic level' than is likely to be so at district/BCU level. Clearly it would be premature at this point to exaggerate the potential tensions that may be generated between specialist units and visible neighbourhood policing. It is of interest to note, however, that among serving officers personal disposition towards amalgamations has been influenced by perceived career advantages (Martis, 2005).

In this context there will be a need for an authority outside the immediate police organisation which is able to monitor levels of police delivery and (more significantly) police abstractions that could quickly serve to question the ability of BCU commanders to provide the level of visible policing predicated on the Neighbourhood Policing Model.

As yet the neighbourhood police model has yet to be fully established. It is also unclear what the potential lifespan of this model might prove to be. The strategy is not set in stone and recent police history offers us a graveyard of 'effective' policing strategies that were subsequently written off or abandoned (e.g. Policing by Objectives 'PBO';'Total Geographic Policing'; Problem Orientated Policing (POP) and 'Community Policing' et $a l$.). It is sometimes difficult to estimate the shelf-life of new policing strategies but experience demonstrates that most do not usually expect to exceed 18 months to two years before succumbing to police 'implementation malaise' and the perceived need for fresh measures or programmes. 
To protect local community interests and policing services there may also be a need to establish boundaries that more accurately reflect local allegiances, business links and crime markets. These matters were overlooked in the course of the 1974 reorganisation and this has meant that police boundaries have often proved to be at some variance with local demands on police forces. This has an immediate relevance to the West Midlands, where former chief officers have publicly acknowledged the real limitations of the 1974 'reorganisation' and the need for further reform. In the case of the West Midlands this was seen as the return of Coventry to the Warwickshire Constabulary as being both necessary and long overdue (Interview Lord Knights, Police Headquarters, Birmingham, 1985).

\section{Local Governance of the Police}

This brief assessment of the potential problems which could arise from the planned police restructuring exercise suggest that at both a police governance and local police operational level there will, in fact, be a clear need for a form of sub-regional government responsibility for policing. This is required if the 'gap' created by regional police structures is to be filled at local level. This issue is of course most pronounced within nonmetropolitan counties. Here, quite unlike their metropolitan counterparts, local districts are neither of the size nor sufficiently resourced to be able either effectively to exercise a governance function or necessarily develop local crime reduction strategies upon which much Level 1 policing activity is now in effect predicated.

The evidence to date indicates that insufficient weight has been attached to the nature and importance of local police governance. One consequence of this failure could, as a result, be to call in question the long-term viability of proposed strategic policing arrangements. More immediately there is a requirement to protect both 'local police functions' and BCU establishments while also providing effective local channels of communication with the communities that are policed.

An important consideration remains that for most police forces and BCUs the overwhelming challenge continues to be, as demonstrated most recently by national survey, that generated by Level 1 crime linked to alcohol use and anti-social behaviour (Police Superintendents Association, 2003). Currently the only feasible platform available for prioritising and channelling local community demands within the planned regional police structure is likely to prove to be a sub-regional government tier that is 
given a joint statutory responsibility for the oversight of the delivery of police services and the delivery of local community safety strategy.

\section{A Rush to Judgement}

Using his powers under the 1996 Police Act the Home Secretary has recently intimated that while hoping that police authorities can reach some agreement concerning the eventual elimination of more than half of them he does not intend to delay the process for an 'inordinate amount of time'. He has also stated that he will not hesitate to dictate to police forces the way forward in terms of amalgamation if they fail to come up with 'their own workable preferences' (Martis, 2005b).

Yet, despite the threat of forced amalgamation, a number of police authorities and police forces are not persuaded as to the advantages of the restructuring proposed by the Home Secretary. Cleveland and West Mercia Police Authorities have rejected the planned mergers and in the case of West Mercia the authority has concluded that the police force could 'stand alone'. This decision has to some degree only reflected the widespread popular opposition within the three counties that make up the force area to any forced amalgamation with the West Midlands. Elsewhere a number of police authorities and forces are actively contemplating judicial review in an attempt to stop their amalgamation with surrounding police forces. In response to this the Home Secretary has intimated, however, that where an authority had embarked on judicial review and had 'wasted money on legal action' he would draw a conclusion 'about the wealth of an authority' that decided to take such action (Martis, 2005b).

It would appear from the forgoing therefore that, along with closing down any exploration of collaboration and federation as meaningful alternatives to police force amalgamation, the Home Secretary also intends to financially penalise any police authority that decides to seek judicial review. This does not seem likely to create the degree of 'consensus and cooperation' that the Home Secretary has also publicly suggested he would like to see surrounding the planned reform of police structures (Martis, 2005a). It is the case, however, that the speed of response demanded by the Home Office from police authorities and forces may well create missed opportunities in terms of effective and long-lasting reform of police boundaries and police governance. Some interesting alternatives involving the use of a federated approach, for example, have been identified by one senior Sussex police officer (Dale, 2005). 
Unfortunately these alternatives are never likely to be evaluated, let alone implemented. It is also apparent that while the curiously break-neck amalgamation exercise initiated by the Home Secretary continues, real reform of policing languishes. As has been argued recently by the Chief Constable of Surrey in relation to 'workforce modernisation', true reform requires the introduction of flexibility and is about 're-engineering working practices' not police force amalgamations (Chief Constable of Surrrey, 2005).

This, as in the past, is an exercise that has demonstrated the appearance rather than the reality of meaningful reform. Of more immediate concern, the likely absence of workforce modernisation is also likely to raise doubts about the long-term viability of the configuration process to which the Home Office Minister has attached such importance. Arguably only the introduction of the modernisation programme can hope to sustain the NIM Level 1 Neighbourhood Policing strategy when big investments, in terms of police establishment, are being made in Level 2 crime.

\section{Conclusion}

The 1996 Police Act gives the Home Secretary the power to initiate police force mergers unilaterally where it appears to him to be expedient to make the alterations in the interests of efficiency and effectiveness. However, the same legislation also provides for a minimum of a four-month period of consultation with relevant parties. This may provide an opportunity for deeper reflection about the nature of police reform than is ever likely to be achieved in the timescale for change identified by the Home Secretary.

The consultation period will hopefully allow for a more comprehensive and meaningful assessment of police force boundaries and the likely impact of further local government reform. This most immediately would need to encompass the issue of police boundaries. This is needed at BCU level in relation to local authorities and in particular their future role in local governance of the police. It will also be needed in relation to the delivery of both community safety and neighbourhood policing strategy at local level.

Professionally there is within senior police circles a commitment to the better provision of protective services. While this may be entirely justified it should not be a commitment that is embarked upon at the expense of better police service provision in terms of Level 1 crime. Ultimately how effective, long-term, the reform programme, particularly in terms of the planned 
reconfiguration process, proves to be will very much depend on the design and structure of the 'reformed' strategic forces. In addition to this the nature and form of police governance at both a strategic and local level will need to be addressed. Only this can be expected to provide the degree of organisational stability that a future reformed police structure will clearly demand.

\section{Note}

* This article is based upon a paper originally prepared for Warwickshire Police Authority and subsequently presented to the Local Government Association Community Safety Advisers Group Meeting, LGA House, December 2005.

\section{Bibliography}

Chief Constable of Surrey (2005). Address to the Association of Police Authorities, Belfast.

Dale, J. (2005) Personal View 'Federal Logic' Police Review $113(5853)$.

HMIC (2005) Closing the Gap. A Review of the Fitness for Purpose of the Current Structure of Policing in England and Wales. London: Home Office.

Loveday, B. (2005a) 'Basic Command Units and Local Authorities'. Paper prepared for the Local Government Association: Safer Communities Advisers Panel, Portsmouth University.

Loveday, B. (2005b) 'The Challenge of Police Reform' Journal of Public Money and Management 25(5).

Loveday, B. (2004) 'Police Reform and Local Government: New Opportunities for Improving Local Community Safety Arrangements in England and Wales' Crime Prevention and Community Safety: An International Journal 6(2): 7-19.

Martis, B. (2005a) 'At the Crossroads', Police Review.

Martis, B. (2005b) 'Home Truths' Police Review 113(5854).

O'Byrne, M. (2001) Changing Policing: Revolution not Evolution. Lyme Regis: PHP.

Pertile, E. (2005a) 'Merging Is Not Enough Says Minister' Police Review 113.

Pertile, E. (2005b) 'Force Merger Proposals Caused "Sleepless Nights" for Inspector' Police Review 113.

Police Superintendents Association (2003) Factors that Impact on BCU Performance.

Police Superintendents Association (2004) Moving Policing Forward.

Young, M. (1991) An Inside Job. Oxford: Oxford University Press. 